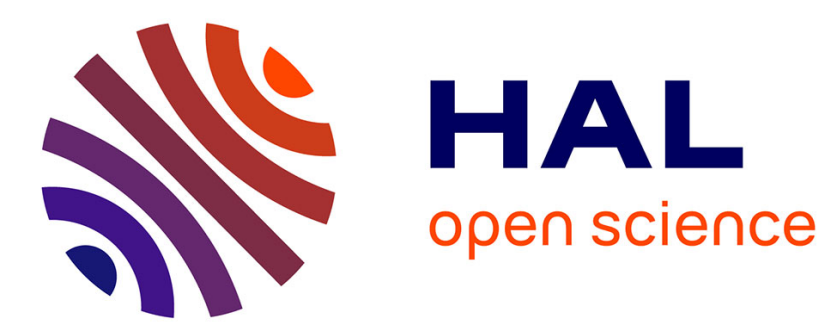

\title{
High termination efficiency using polyimide trench for high voltage diamond Schottky diode
}

\author{
Houssam Arbess, Karine Isoird, Moustafa Zerarka, Henri Schneider, \\ Marie-Laure Locatelli, Dominique Planson
}

\section{- To cite this version:}

Houssam Arbess, Karine Isoird, Moustafa Zerarka, Henri Schneider, Marie-Laure Locatelli, et al.. High termination efficiency using polyimide trench for high voltage diamond Schottky diode. Diamond and Related Materials, 2015, 58, pp.149-154. 10.1016/j.diamond.2015.07.006 . hal-01218796

\section{HAL Id: hal-01218796 \\ https://hal.science/hal-01218796}

Submitted on 21 Oct 2015

HAL is a multi-disciplinary open access archive for the deposit and dissemination of scientific research documents, whether they are published or not. The documents may come from teaching and research institutions in France or abroad, or from public or private research centers.
L'archive ouverte pluridisciplinaire HAL, est destinée au dépôt et à la diffusion de documents scientifiques de niveau recherche, publiés ou non, émanant des établissements d'enseignement et de recherche français ou étrangers, des laboratoires publics ou privés. 


\title{
High termination efficiency using polyimide trench for high voltage diamond Schottky diode
}

\author{
Houssam ARBESS ${ }^{\mathrm{a}, \mathrm{b}, *}$, Karine ISOIRD ${ }^{\mathrm{b}, \mathrm{d}}$, Moustafa ZERARKA ${ }^{\mathrm{b}, \mathrm{c}}$, Henri SCHNEIDER ${ }^{\mathrm{b}, \mathrm{d}}$, Marie- \\ Laure LOCATELLI ${ }^{\mathrm{e}}$, Dominique PLANSON ${ }^{\mathrm{f}}$ \\ ${ }^{a}$ University of Bordeaux, Bordeaux Institute of Technology, IMS Laboratory \\ CNRS UMR 5218, F-33400, Talence, France \\ ${ }^{\mathrm{b}} \mathrm{LAAS}$ - CNRS, 7 avenue du colonel Roche, F-31400 Toulouse, France \\ ${ }^{\mathrm{c}}$ Univ de Toulouse, LAAS, F-31400 Toulouse, France \\ ${ }^{\mathrm{d}}$ Univ de Toulouse, UPS, LAAS, F-31400 Toulouse, France \\ ${ }^{\mathrm{e}}$ Université de Toulouse, UPS, INPT, LAPLACE (Laboratoire Plasma et Conversion d'Energie), 118 \\ route de Narbonne, F-31062 Toulouse cedex 9, France CNRS, LAPLACE, F-31062 Toulouse, France \\ ${ }^{\mathrm{f}}$ Université de Lyon, CNRS, Laboratoire AMPERE, UMR 5005, INSA de Lyon, F-69621 \\ Villeurbanne, France
}

\begin{abstract}
Using finite element simulations with Sentaurus TCAD (Technology Computer-Aided Design) software, a progress from simple and classic termination for a Schottky diode to new topology termination has been studied in this paper. A polyimide trench under field plate termination has been used. The efficiency increases from $67 \%$ for a simple field plate with optimum parameters up to $97 \%$. The maximum electric field in the termination dielectric has been evaluated also. A wide study of the termination geometry has been made in order to extract the optimum parameters in two directions. The first one is to obtain a high efficiency regarding the breakdown voltage, and the second one is to have the minimum electric field peak at the termination edge.
\end{abstract}

Keywords: Diamond, TCAD Simulation, Field plate, Termination, Schottky, Polyimide.

\section{Introduction}

Due to its super properties such as high breakdown field, high saturation velocity, high carrier mobility and the highest thermal conductivity of all materials, diamond becomes the best material for the power devices [1]. At high temperature, the conventional semiconductors cannot be used because of intrinsic carrier generation across the band gap. For these cases wide band gap semiconductor materials like $\mathrm{SiC}, \mathrm{GaN}$, and diamond are promising candidates. For example, due to a band-gap energy of $5.45 \mathrm{eV}$ the diamond intrinsic carrier concentration at $1000^{\circ} \mathrm{C}$ is in the range of $10^{10} \mathrm{~cm}^{-3}$, which is similar to that of Silicon at room temperature and similar device performance may be expected [2]. Therefore, diamond is a very attractive material for high temperature, high-voltage and high-power switching applications in future power electronics.

The device under study in this paper is a diamond $\mathrm{P}$ type Schottky diode. As all power devices, a junction termination is needed in order to spread the equipotential lines, to reduce the electric field at the edge of devices and to reach the theoretical breakdown voltage. Several junction terminations have been explored for the Schottky diode in wide-band-gap semiconductors. Some of the more common ones are the guard ring [3,4], the metal field plates extending over an insulating surface layer [5], [6], resistive Schottky barrier field plate (RESP) [7], and junction-termination extension (JTE) [8].

Due to difficulties associated with donor atom doping in diamond and destructive effects of ion implantation on the diamond crystal, N-type region is not yet optimized. Therefore, techniques commonly used for terminating $\mathrm{Si}$ or $\mathrm{SiC}$ devices, such as field rings or junction termination extensions, cannot be employed for diamond. That's why the field plate termination is chosen for this study. 
Several materials and architectures have been used in order to optimize the efficiency of the field plate termination. Due to its high dielectric permittivity, Ikeda [5,9] used the aluminum oxide $(\mathcal{E} \approx 9)$ as a dielectric under the field plate. His results show an increasing of breakdown voltage from $200 \mathrm{~V}$ without termination to $700 \mathrm{~V}$ with field plate. Brezeanu $[10,11]$ used the graduated, ramp dielectric form and high $\mathrm{K}$ dielectric under field plate in order to increase the breakdown voltage. Thion [12] used semi-resistive material upon a layer of silicon nitride in order to diffuse the equipotential lines and therefore decrease the maximum electric field and increase the breakdown voltage.

The results of Thion [13] show a difference between simulated and experimental results. One of the reasons can be the electric field peak at the edge of the termination. This peak is probably higher than the crictical field of the dielectric used under the field plate.

The principal goal of this study is to decrease the maximum electric field peak in the structure, which is normally localized at the edge of termination, using polyimide trench under field plate.

An architecture using a polyimide trench under field plate has been studied in this paper. Several architecture with many geometrical parameters have been tried in order to extract the optimum values and geometry.

\section{Diamond Schottky diode simulation parameters}

The structure under study is a diamond pseudo vertical Schottky diode. The technological and geometrical parameters were chosen using TCAD (Technology Computer-Aided Design) simulation to have a breakdown voltage equal to $1700 \mathrm{~V}$ at room temperature. One dimension simulations with Sentaurus have been made in order to extract these parameters. Assuming that, the termination efficiency is around $85 \%$, that means, the insures a breakdown voltage equals $85 \%$ of the breakdown voltage of the ideal component (one dimension simulation), the thickness of $\mathrm{P}^{-}$layer should be equal to 11 or $12 \mu \mathrm{m}$ with boron doping concentration equal to $2 \times 10^{15}$ or $4 \times 10^{15} \mathrm{~cm}^{-3}$ successively. The second parameters set $\left(12 \mu \mathrm{m} ; 4 \times 10^{15} \mathrm{~cm}^{-3}\right)$ have been chosen because simulation results show a forward current density greater than for the first parameters set $\left(11 \mu \mathrm{m} ; 2 \times 10^{15} \mathrm{~cm}^{-3}\right)$ at ON state. So, the structure consists of two diamond layer (Fig. 1), the first is a $7 \mu \mathrm{m} \mathrm{P}^{+}$doped diamond with a doping concentration of $3 \times 10^{20} \mathrm{~cm}^{-3}$ and the other is a $12 \mu \mathrm{m} \mathrm{P}$-doped diamond with doping concentration of $4 \times 10^{15} \mathrm{~cm}^{-3}$.The physical model used to calculate the breakdown voltage is the default Van Overstraeten model [14-16] with parameters value given in the paper of Rashid et al [17]. The carrier mobility, maximum electric field and other parameters are detailed in the thesis report of Thion [13].

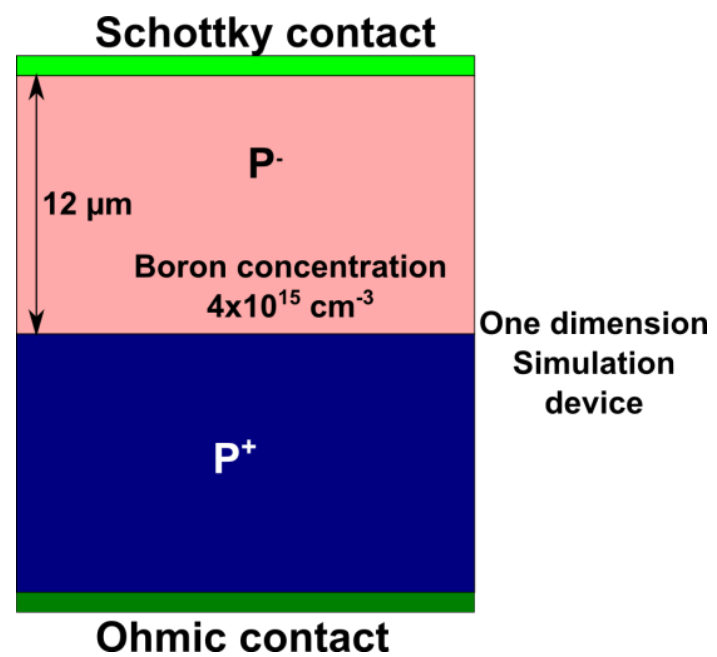

Fig. 1: One dimension simulation structure for diamond Schottky diode.

Due to convergence problem at low temperature, all simulations in this paper have been made at 800K. The electrical characterizations of this Schottky diode have been extracted by extrapolation after simulations at different temperatures. Other simulations have been made in order to evaluate the variation of the electric field with temperature shown a negligible difference. 
The polyimide dielectric material has been used for all simulations as a secondary passivation.

\section{New termination architecture}

Many field plate termination architectures have been used in majority of simulations in order to increase the breakdown voltage without noticing of the electric field peak at the end of field plate. Indeed, the case of diamond is specific, and due to its high critical field, which is much larger than that of the dielectrics frequently used in power devices, the electric field peak in the termination is very high. So, it is necessary to design new termination architectures that reduce drastically the electric field in the dielectrics.

In previous papers $[18,19]$ an idea has been proposed to increase the efficiency of the field plate by eliminating the electric field peak in the diamond (Fig. 2 - structure B). It is to keep the whole electrode flat, with no corners, and replace the diamond below the field plate region, with an optimized thickness of a dielectric material. This idea is not used to decrease the electric field peak value at the end of the field plate (almost $60 \mathrm{MV} / \mathrm{cm}$ at $1700 \mathrm{~V}$ ). Several termination architecture (pillars dielectric form, graduated dielectric form and mixed dielectric form) with different dielectric materials (silicon oxide and aluminum oxide) $[18,20]$ have been proposed in order to decrease the electric field peak at the end of the field plate.

The electric field by definition is the potential variation in a given distance. If the potential lines in the structure can be displaced away the field plate, the maximum electric which located at the edge of field plate decreases. To achieve the spread of equipotential lines, it is necessary to use a dielectric with a value of permittivity smaller than the diamond in the lower part of the termination structure. An idea consists to make polyimide trench under the field plate (Fig. 2 - structure C). The used dielectric in this paper is the silicon oxide. Theolier [21,22] has used this technique to design efficiency termination of superjunction silicon MOSFET (Deep Trench Termination $\mathrm{DT}^{2}$ ), but by using the BCB (Benzo-Cyclo-Butene) as a dielectric in place of polyimide. The polyimide is a sort of polymer [23,24]. Its critical field is around $5 \mathrm{MV} / \mathrm{cm}$. One of its use is for second passivation in the microelectronic devices and particularly for high voltage and high temperature SiC devices [25], which encourages the use of this material is the facility of the deposit and its permittivity very close to the silicon oxide $(\approx 3)$ that's mean, smaller than that of diamond $(\approx 5.7)$.

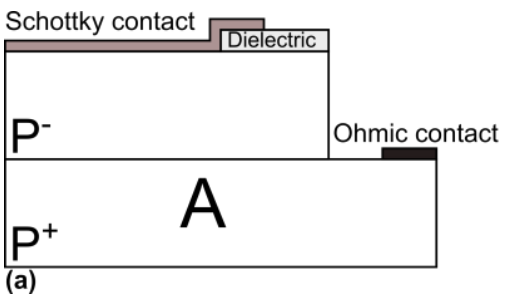

Fig. 2: Field plate architectures. From (a) to (c), classic architecture, advanced architecture [18] and with polyimide trench

\subsection{Technological process}

Due to several reasons, the necessary technological processes to make diamond components are specifics. The small wafer dimension $(3 \mathrm{~mm} \times 3 \mathrm{~mm})$ and the difficulty to make a local doping are some of the more reason. In this case, the technological process which is able to make the diamond Schottky diode with the new termination, are describe in Fig. 3. The anode contacts of the all diodes is the wafer are interconnected. After etching until the $\mathrm{P}^{+}$layer, ohmic contacts must be made before the deposit of the polyimide layer. After the polymerization of the polyimide and the CMP (Chemical Mechanical Polish) process, the time of the silicon oxide deposit layer becomes. The final processes are the deposit of the Schottky contact and the etching of the polyimide at the edge of the wafer in order to have an access to the anode contacts. 


\begin{tabular}{|l|}
\hline $\mathrm{P}^{-}$layer \\
\hline $\mathrm{P}^{+}$layer \\
\hline
\end{tabular}
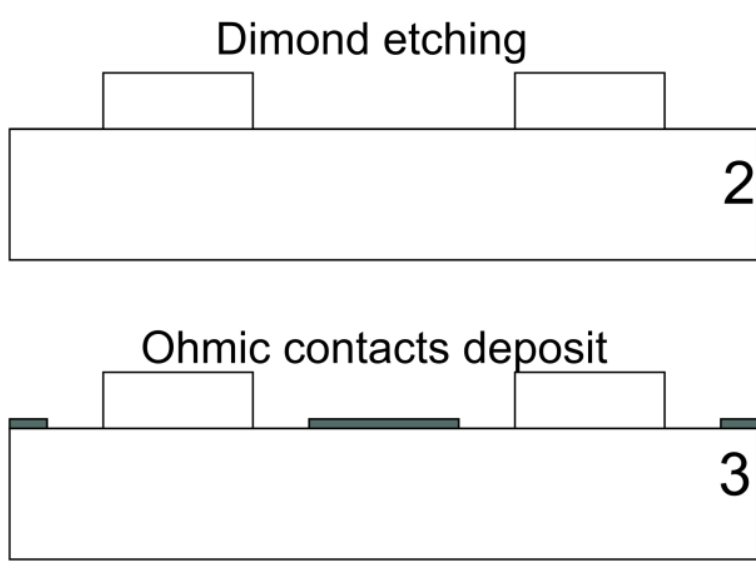

Polyimide deposit and polymerization

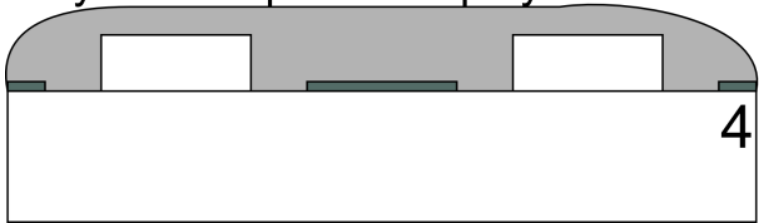

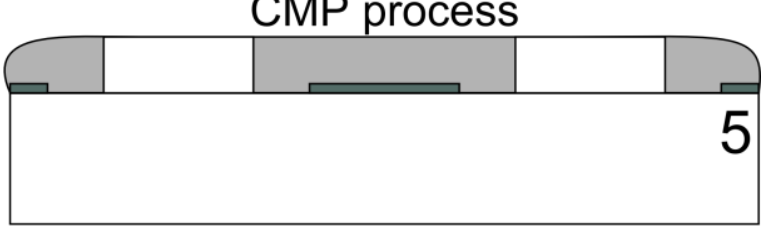

Silicon oxide deposit

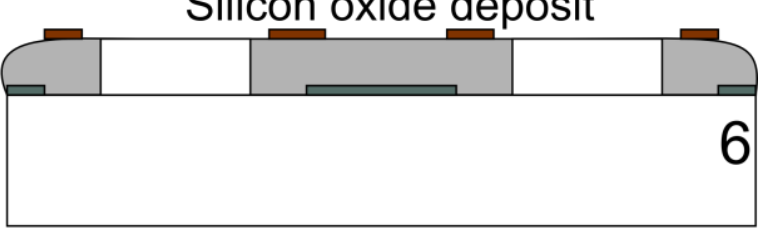

Schottky contact deposit
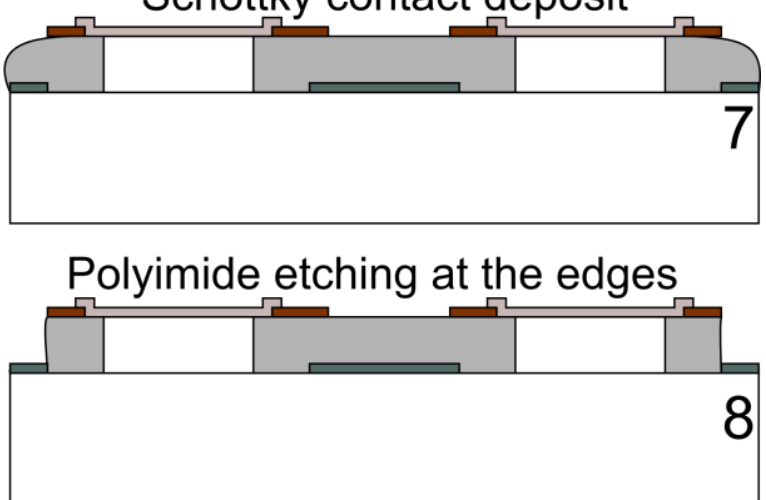

Fig. 3: Technological steps for diamond Schottky diode

\subsection{Architecture parameters and results}

The depth of the polyimide in this structure equals the diamond $\mathrm{P}^{-}$one. The field plate on the polyimide, as Fig. 2 (c) shows, is in the classic form. Three interest parameters can be effective in this architecture: the dielectric thickness, the field plate extension length and the position of the dielectric (Fig. 4).

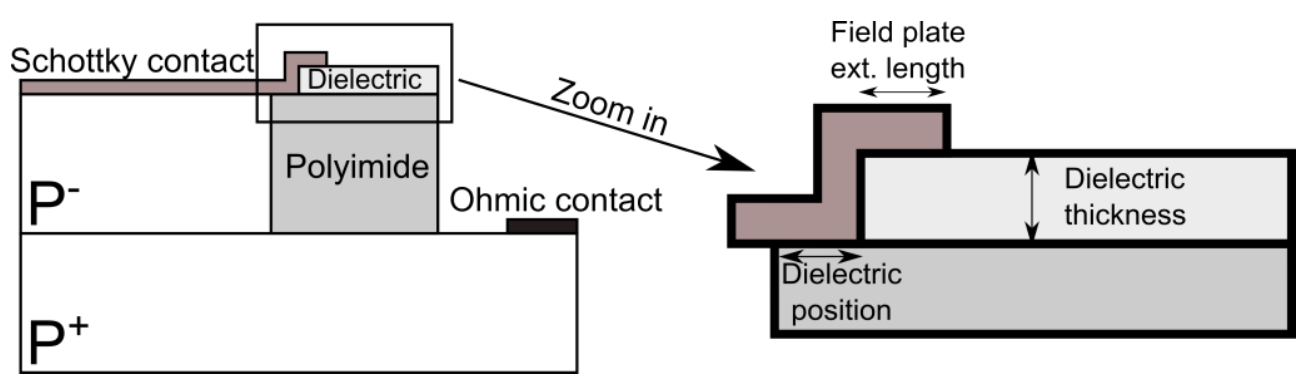

Fig. 4: Termination architecture with polyimide trench

\subsubsection{Parameters effect on the breakdown voltage}

The dielectric (silicon oxide) thickness was varied from 0 to $2 \mu \mathrm{m}$, the field plate extension length from 0.5 to $15 \mu \mathrm{m}$ and the position of the dielectric from 0 to $10 \mu \mathrm{m}$. The variation of these parameters shows a negligible effect on the breakdown voltage. The obtained efficiency with all these parameters was equal to $97 \%$. Indeed, the polyimide trench make the electric field homogeneous along horizontal axis passing through the diamond (Fig. 5), and as a result, the impact ionization is homogenous in the structure and there is not a weak point. Fig. 6 shows the impact ionization at breakdown for the three architectures respectively for the structure A, B and C at $2780 \mathrm{~V}, 3300 \mathrm{~V}$ and $4000 \mathrm{~V}$. The impact ionization in Fig. 6-c is almost homogeneous in the diamond and does not have a weak point as the architecture of Fig. 6-a and b. 


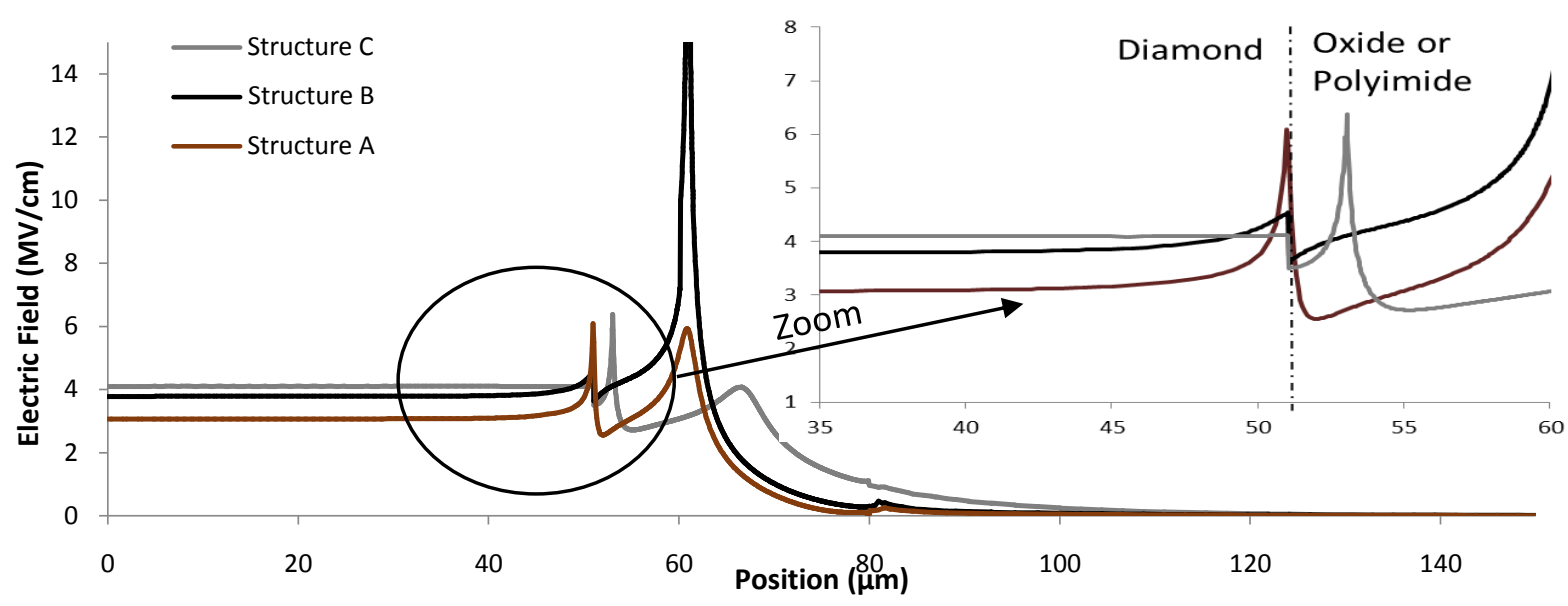

Fig. 5: Electric field along horizontal axis passes at the diamond surface (0.1 $\mu \mathrm{m}$ of depth) at breakdown
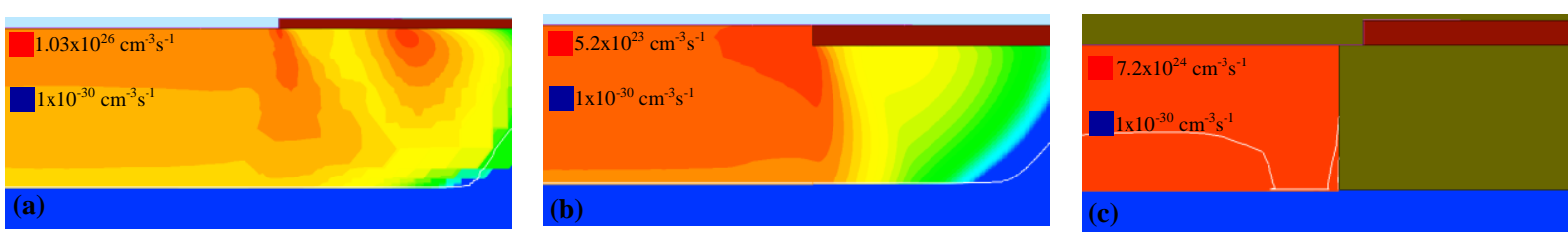

Fig. 6: Impact ionization at the breakdown for the structures of Fig. 2. ((a) at $2781 \mathrm{~V}$, (b) at $3300 \mathrm{~V}$ and (c) at $4000 \mathrm{~V})$

In some cases, the efficiency of the termination is smaller than $97 \%$ : If the position of the dielectric (under extension field plate) is close to the beginning of the polyimide (smaller than $3 \mu \mathrm{m}$ ), the efficiency decreases down to $88 \%$ if the position of the dielectric equals 0 and its thickness equal 2 $\mu \mathrm{m}$. Indeed, the variation of the direction of the equipotential lines increases the electric field at this edge (begin of the field plate). This punctual increasing has a result of premature breakdown.

The polyimide trench has a positive effect to the maximum electric field peak. Indeed, Fig. 7 shows the equipotential lines at $1700 \mathrm{~V}$ for the structures B and C successively Fig. 7-a and Fig. 7-b. For the first case (a), the electrostatic potential lines have a direction to the up there are very tight. That means high potential variation in small distance and as a result, high electric field. In the second case (b), the electrostatic potential lines change their direction downward after entering the polyimide trench. This variation of direction makes the potential variation smaller than for the first case in the same distance and as a result the electric field decreases.
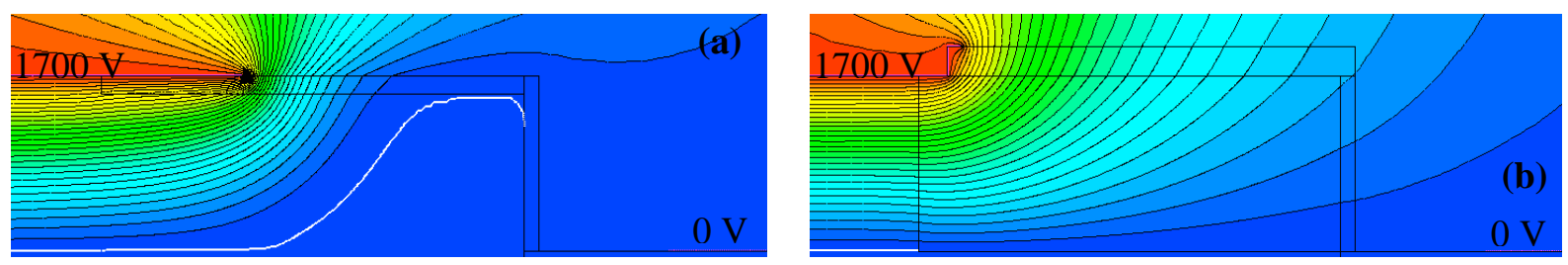

Fig. 7: Equipotential lines at $1700 \mathrm{~V}$ for the structures of Fig. $2 \mathrm{~b}$ and $\mathrm{c}$ respectively from left to right

This structure is simulated with a polyimide as a second passivation which has a negligible effect on the breakdown voltage.

\subsubsection{Parameters effect on the maximum electric field peak}

Since the Schottky diode is designed to operate at $1700 \mathrm{~V}$, the maximum electric field values have been extracted at $1700 \mathrm{~V}$. The node-to-node distance in the simulation mesh has a great effect to the electric field peak value in the dielectric. Therefore, all comparisons in this paper have been made in the same node-to-node distance $(10 \mathrm{~nm})$.

The variation of geometrical parameters has now an enormous effect. The electric field peak at the edge of field plate decreases when increasing the thickness of the dielectric under field plate extension 
from $20 \mathrm{MV} / \mathrm{cm}$ with $1.2 \mu \mathrm{m}$ of dielectric thickness down to $17 \mathrm{MV} / \mathrm{cm}$ with $2.2 \mu \mathrm{m}$ of dielectric thickness (Fig. 8). The position of the dielectric in this case equals $11 \mu \mathrm{m}$ and the extension field plate length equals $1 \mu \mathrm{m}$. Note that, the increase in dielectric thickness has a minor negative effect on the breakdown voltage.
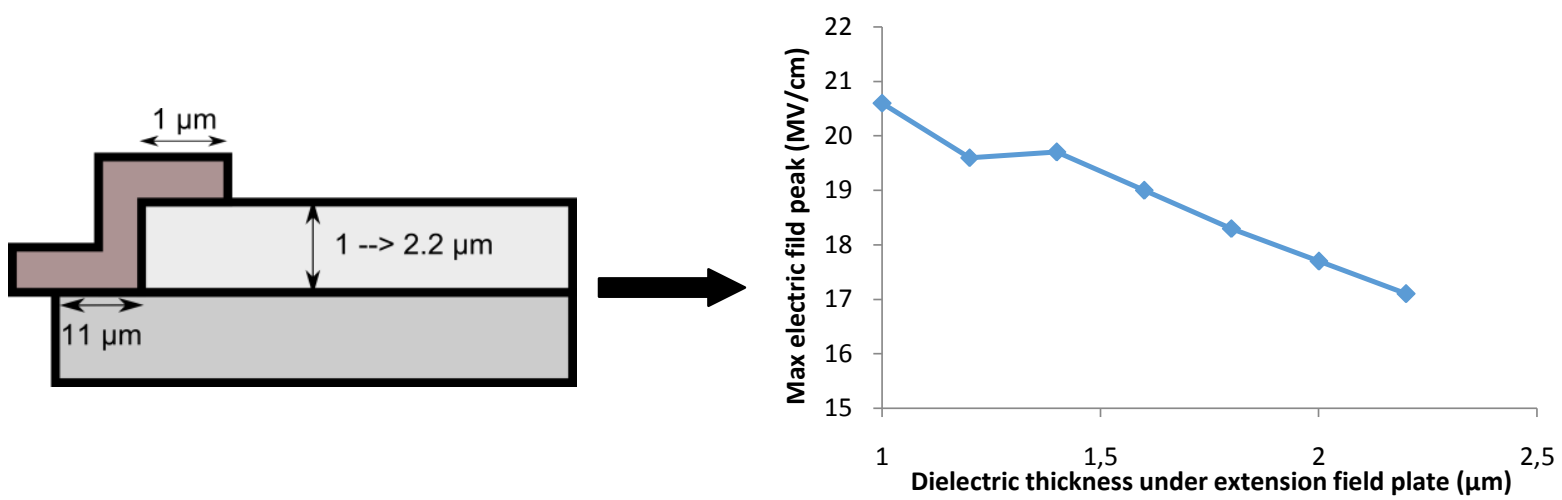

Fig. 8: Variation of the maximum electric field peak in terms of dielectric thickness under extension field plate

Increasing the extension field plate length, the maximum electric field peak increases. For example passing from $0.5 \mu \mathrm{m}$ to $4 \mu \mathrm{m}$, the maximum electric field peak increases from $13.3 \mathrm{MV} / \mathrm{cm}$ up to 20.5 $\mathrm{MV} / \mathrm{cm}$ (Fig. 9). With this variation, the minimum feasible value of the extension field plate length is the best. The diamond cheap dimensions equal to $(3 \mathrm{~mm} * 3 \mathrm{~mm})$, so, the classic photolithography machine has been used to make the mask. For this machine, the precision is equal to $1 \mu \mathrm{m}$.
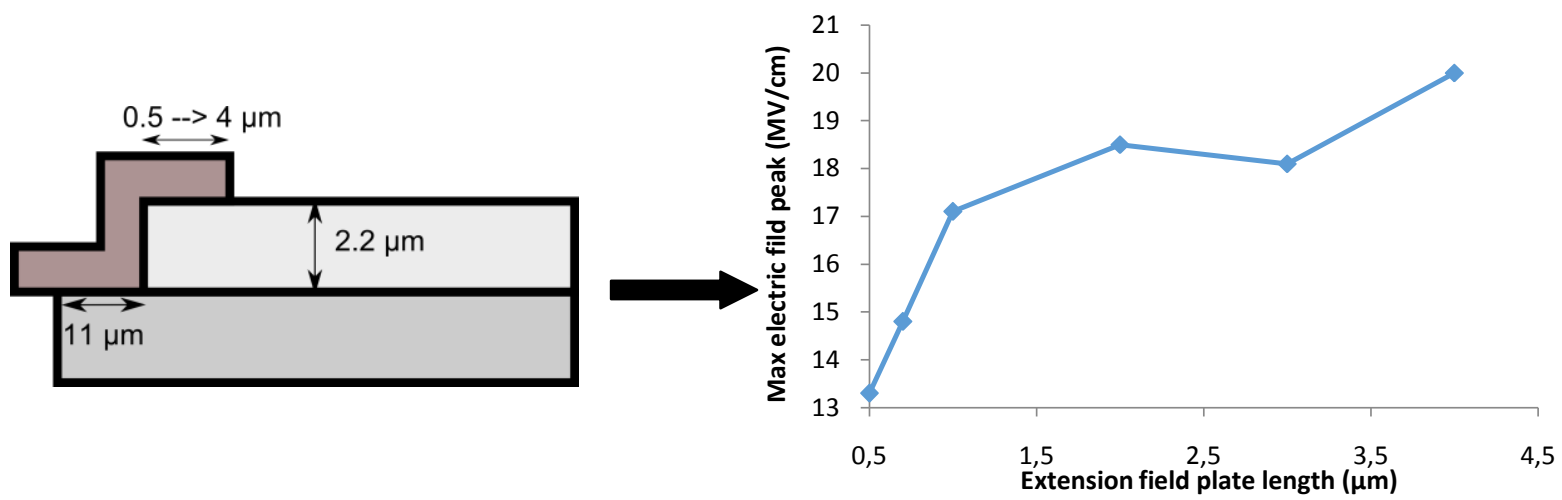

Fig. 9: Variation of the maximum electric field peak in terms of extension field plate length

The position of the dielectric has a small effect while it's far from the beginning of the polyimide trench. Passing from $1 \mu \mathrm{m}$ to $15 \mu \mathrm{m}$ the maximum electric field peak decrease from 18.5 down to 17 $\mathrm{MV} / \mathrm{cm}$ (Fig. 10). As shown before, this variation has an impact on the breakdown voltage. Indeed, the presence of a corner close the semiconductor (diamond) increases the impact ionization and as a conclusion the breakdown voltage decreases. 


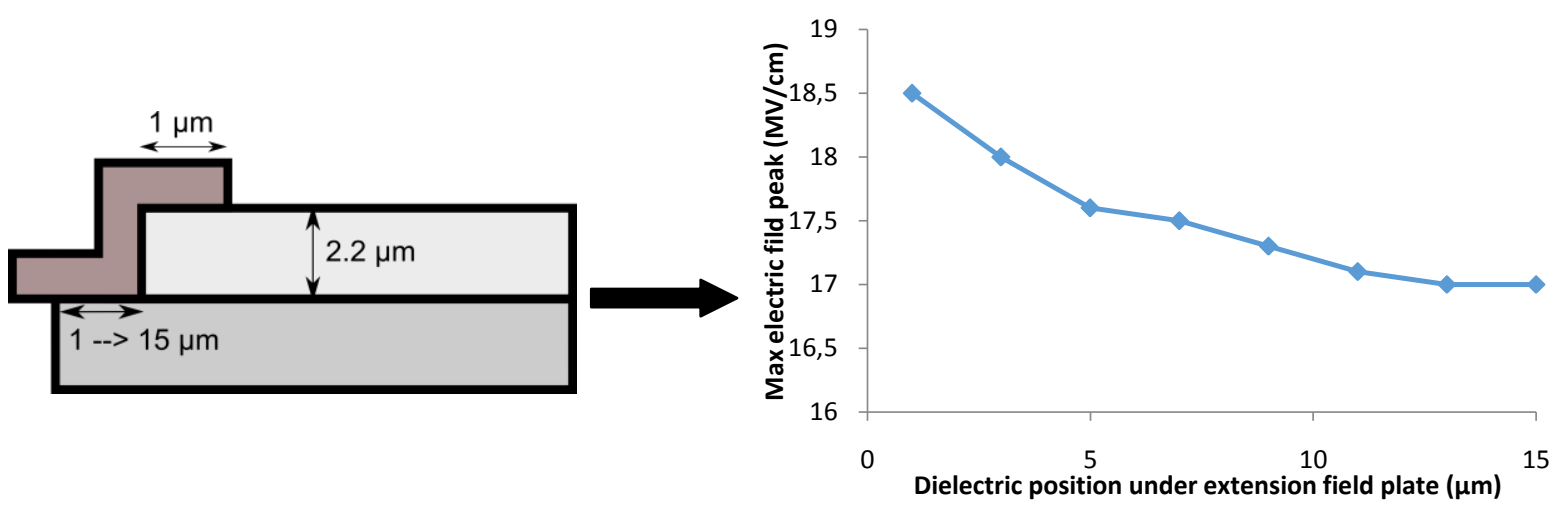

Fig. 10: Variation of the maximum electric field peak in terms of extension field plate length

With this architecture the maximum field peak is around $25 \mathrm{MV} / \mathrm{cm}$. If the pillars dielectric form or the graduated dielectric form replaces the simple field plate [18], the maximum electric field can be decreases to $18 \mathrm{MV} / \mathrm{cm}$ with 4 pillars and $2 \mu \mathrm{m}$ of thickness and $20 \mathrm{MV} / \mathrm{cm}$ with 3 graduations and 2 $\mu \mathrm{m}$ for each graduation.

\section{Conclusion}

In this paper, new termination architecture has been applied for $1700 \mathrm{~V}$ diamond Schottky diode. The termination efficiency has been increased from $67 \%$ for a simple field plate with optimum parameters to $97 \%$ for new topology with polyimide trench under the field plate. The maximum electric field problem at the end of the field plate has been studied also. Several parameters of the new architecture have been simulated in order to obtain the minimum of the electric field peak. It can be arrived to $13 \mathrm{MV} / \mathrm{cm}$ of this peak with high precision of the photolithography process. This value remains greater than the critical field of silicon oxide, but ten times smaller than for the classical field plate.

\section{Acknowledgements}

This study was conducted in the framework of the topic "simulation, design and realization of high voltage and high temperature power devices" of the LIA (International Laboratory) WIDE-Lab (Wide bandgap technologies for Integration of energy efficient Devices), composed by two French laboratories LAAS and Ampere affiliated at CNRS, and IBM/CNM CSIC laboratory. This work was supported by French FUI project DIAMONIX2

\section{References}

[1] Sussmann R S. CVD Diamond for Electronic Devices and Sensors. John Wiley \& Sons, 2009.

[2] Vescan A, Daumiller I, Gluche P, Ebert W, Kohn E. Very high temperature operation of diamond Schottky diode. IEEE Electron Device Lett., vol. 18, nº 11, p. 556-558, 1997.

[3] Gupta S K, Pradhan N, Shekhar C, Akhtar J. Design, Fabrication, and Characterization of Ni/4HSiC (0001) Schottky Diodes Array Equipped With Field Plate and Floating Guard Ring Edge Termination Structures. IEEE Trans. Semicond. Manuf., vol. 25, nº 4, p. 664-672, 2012.

[4] Ueno K, Urushidani T, Hashimoto K, Seki Y, The guard-ring termination for the high-voltage SiC Schottky barrier diodes. IEEE Electron Device Lett., vol. 16, nº 7, p. 331-332, 1995.

[5] Ikeda K, Umezawa H, Tatsumi N, Ramanujam K, Shikata S. Fabrication of a field plate structure for diamond Schottky barrier diodes . Diam. Relat. Mater., vol. 18, n 2-3, p. 292-295, Feb. 2009.

[6] Tarplee MC, Madangarli VP, Zhang Q, Sudarshan TS. Design rules for field plate edge termination in SiC Schottky diodes. IEEE Trans. Electron Devices, vol. 48, $\mathrm{n}^{\mathrm{o}}$ 12, p. 2659-2664, 2001. 
[7] Bhatnagar M, Nakanishi H, Bothra S, McLarty P K, Baliga B J, Edge terminations for SiC high voltage Schottky rectifiers. In: Proceedings of the 5th International Symposium on Power Semiconductor Devices and ICs, 1993. ISPSD '93, p. 89-94.

[8] Alok D, Baliga BJ. SiC device edge termination using finite area argon implantation. IEEE Trans. Electron Devices, vol. 44, nº 6, p. 1013-1017, 1997.

[9] Ikeda K, Umezawa H, Shikata S. Edge termination techniques for p-type diamond Schottky barrier diodes. Diam. Relat. Mater., vol. 17, nº 4-5, p. 809-812, April. 2008.

[10]Brezeanu M, Avram M, Rashid SJ, Amaratunga GAJ, Butler T, Rupesinghe NL, Udrea F, Tajani A, Dixon M, Twitchen DJ, Garraway A, Chamund D, Taylor P, Brezeanu G. Termination Structures for Diamond Schottky Barrier Diodes. In: IEEE International Symposium on Power Semiconductor Devices and IC's. ISPSD 2006, p. 1 -4.

[11]Brezeanu M, Butler T, Rupesinghe NL, Amaratunga GAJ, Rashid SJ, Udrea F, Avram M, Brezeanu G. Ramp oxide termination structure using high-k dielectrics for high voltage diamond Schottky diodes. Diam. Relat. Mater., vol. 16, nº 4-7, p. 1020-1024, April, 2007.

[12]Thion F, Isoird K, Planson D, Locatelli M-L, Ding H. Simulation and design of junction termination structures for diamond Schottky diodes. Diam. Relat. Mater., vol. 20, $\mathrm{n}^{\mathrm{o}}$ 5-6, p. $729-$ 732, May 2011.

[13]Thion F. Conception de protections périphériques applicables aux diodes Schottky réalisées sur diamant monocristallin. Thesis report, INSA de Lyon, 2012.

[14]« Sentaurus user guide A-2008.09 ». .

[15]Chynoweth AG. Ionization Rates for Electrons and Holes in Silicon. Phys. Rev., vol. 109, $\mathrm{n}^{\mathrm{o}}$ 5, p. 1537-1540, March 1958.

[16]Van Overstraeten R, De Man H. Measurement of the ionization rates in diffused silicon p-n junctions. Solid-State Electron., vol. 13, nº 5, p. 583-608, May 1970.

[17]Rashid SJ, Tajani A, Coulbeck L, Brezeanu M, Garraway A, Butler T, Rupesinghe NL, Twitchen DJ, Amaratunga GAJ, Udrea F, Taylor P, Dixon M, Isberg J. Modelling of single-crystal diamond Schottky diodes for high-voltage applications. Diam. Relat. Mater., vol. 15, $\mathrm{n}^{\mathrm{o}} 2-3$, p. 317-323, Feb. 2006.

[18] Arbess H, Isoird K, Hamady S. New termination architecture for $1700 \mathrm{~V}$ diamond Schottky diode. In: 2013 15th European Conference on Power Electronics and Applications (EPE), 2013, p. 1-8.

[19] Nawawi A. Tseng KJ, Rusli, Amaratunga GAJ, Umezawa H, Shikata S. Design and optimization of planar mesa termination for diamond Schottky barrier diodes. Diam. Relat. Mater., vol. 36, p. 51-57, June 2013.

[20] Arbess H, Isoird K. Field plate termination for high voltage diamond Schottky diode. In: 2013 25th International Conference on Microelectronics (ICM), 2013, p. 1-4.

[21]Theolier L, Isoird K, Morancho F, Roig J, Mahfoz-Kotb H, Brunet M, Dubreuil P. Deep trench MOSFET structures study for a 1200 Volts application. In: 2007 European Conference on Power Electronics and Applications, 2007, p. 1-9.

[22]Théolier L, Mahfoz-Kotb H, Isoird K, Morancho F. A new junction termination technique: The Deep Trench Termination $\left(\mathrm{DT}^{2}\right)$. In: 21st International Symposium on Power Semiconductor Devices IC's, 2009. ISPSD 2009, p. 176-179.

[23]Chiang P-C, Whang W-T. The synthesis and morphology characteristic study of BAO-ODPA polyimide/TiO2 nano hybrid films. Polymer, vol. 44, nº 8, p. 2249-2254, April. 2003.

[24]Ghosh M. Polyimides: Fundamentals and Applications. CRC Press, 1996.

[25] Zelmat S, Locatelli M-L, Lebey T, Diaham S. Investigations on high temperature polyimide potentialities for silicon carbide power device passivation. Microelectron. Eng., vol. 83, $\mathrm{n}^{\mathrm{o}} 1$, p. 51-54, Jan. 2006. 